\title{
A Woman with Anxiety Symptoms: Did a Diary Help to Reduce them?
}

\author{
Patricia Yuannita Tunrisna ${ }^{\mathrm{a}}$ and Lathifah Hanum ${ }^{\mathrm{b}}$ \\ ${ }^{a}$ Clinical Adult Magister-Profession, Faculty of Psychology, Universitas Indonesia, Depok, \\ Indonesia; ${ }^{b}$ Clinical Psychology Department, Faculty of Psychology, Universitas Indonesia, \\ Depok, Indonesia.
}

*Corresponding Author:

Lathifah Hanum

Clinical Psychology Department

Faculty of Psychology, Universitas Indonesia

Jl. Lkr. Kampus Raya, Depok, Jawa Barat

Indonesia, 16424

Tel.: +62 217270004

E-mail address: lathifah.hanum08@ui.ac.id 


\title{
A Woman with Anxiety Symptoms: Did a Diary Help to Reduce Them?
}

\begin{abstract}
Anxiety can disrupt functioning of individuals in everyday life, but the symptoms are sometimes not recognized. This case study is about an inferior and self-centered woman who experiences anxiety. This anxious feeling is interferes with many of her daily activities; it also makes her stutter, so she ends up crying because she feels nobody will understand her. She cannot show her best performance in everyday life and is very afraid of judgment by others. Because of this, she has become very dependent on others, too. This poor self-concept is also influenced by authoritarian parenting. An authoritarian parenting pattern makes it difficult for an individual to learn how to make decisions, since she is always directed. This makes her untrained in how to behave and make decisions, so that anxiety naturally arises when she is required to do so within a particular environment. Therefore, the purpose of this study is to see if expressive writing interventions can decrease anxiety symptoms. Diary writing activities are the main activities she does every day. In addition, researchers provide progressive relaxation training at face-to-face meetings, as well as drawing activities in two of the sessions because she really enjoys expressing herself through depiction. These activities support a decrease in anxiety. To assess the effect, we observe her progress over 4 to 8 weeks. Through this observation, we can see changes related to lower anxiety levels every day. This case study demonstrates that the application of a diary can decrease a client's apprehensive anxiety.
\end{abstract}

Keywords: Anxiety, observation, parenting, and progressive relaxation training

\section{Introduction}

In everyday life sometimes people are unaware or less able to recognize the anxiety symptoms they feel. Without awareness of anxiety's symptoms, our daily performance can be affected. This case study $(n=1)$ is about a woman named Prily who is 20 years old. She complains of experiencing anxiety, which she describes as feeling very uncomfortable. Kring, Johnson, Davison, and Neale (2012) state that anxiety tends to focus on future threats. Worrying about future threats often involves moderate arousal, while feeling fearful involves higher arousal. Not everyone experiences anxiety from the same sources. Prily feels anxious when she has to convey her feelings or opinions to others. She wondered if in fact she was the only one who felt anxious about things that others think are trivial. According to Shri (2010), anxiety is a subjective feeling of unease, discomfort, apprehension or fearful concern accompanied by a host of autonomic and somatic manifestations. When Prily tried to convey an opinion, she stuttered. This stuttering behavior occurred even when she did not have to speak in front of a crowd. This unpleasant experience started when she was in high school. Prily felt that the older she got, the more responsibilities she had, and this made her even more anxious. Her anxiety also arises for other reasons besides expressing her opinions; learning to make her own decisions also makes her anxious. As she got older, she felt more anxious when she made a wrong decision and disappointed herself or her parents. She also began to notice and worry about how others were judging her one day while sitting in 11th grade in high school. According to Arnet (as cited in Mahmoud, Staten, Hall, and Lennie, 2012), the group aged 18-24 years or the "growing adult group" marks the development stage for the transition between late adolescence and adulthood. Stress and anxiety become a commonplace experience during this transitional period. Meadows, Brown, and Elder (2006) stated that this particular transition requires skills development to 
maintain self-reliance and individual independence through time of experiencing intimate relationships, pain, and anxiety.

Prily was formerly a gifted and accomplished student; she also had good support from her teachers, friends, and family. Her parents were very attentive and self-directed. However, her time was always arranged by her parents and she had to do what was chosen by them for her. This authoritarian parenting is a form of restriction that includes a style of punishment in which parents urge children to follow their direction closely (King, 2014). Authoritarian parenting styles often result in adolescent conflict, opposition or resistance, and adolescent dependence on parents (Rice, 1996). As a result, teenagers typically become anxious about social comparisons, failing in creative activities, and ineffective in social interactions (Santrock, 1995). In addition, Hill \& Steinberg (as cited in Santrock, 1995) also stated that authoritarian parenting is associated with low child independence. Authoritarian parents are also less warm than other parents. Their children tend to seem withdrawn and display a lack of trust.

Nowadays, there has been a lot of research on therapy for how to handle anxiety. One therapy option is to write a journal, keep a diary, or draw. Over the last decade, a great deal of research has been done showing that when individuals write about emotional experiences, significant physical and mental health improvements tend to follow (Pennebaker, 1997). According to Murnahan (2010), for centuries, writing for oneself has become an important form of selfreflection and self-therapy. Individuals who have emotional experiences find ways of expressing themselves by writing down their thoughts and feelings. Research by Pennebaker (1997) suggests that expressive writing can relieve symptoms of stress and anxiety. This is reinforced by Sloan \& Marx' (2004a) research; they found that expressive writing had a positive impact on one's physical and mental health. When writing and drawing, the researchers provide a guide to the questions which, according to Keeling and Bermudez (2006), guides writer in their research to help focus attention on that problem. Carlson (as cited in Keeling and Bermudez, 2006) states that drawing a narrative story is also a form of individual externalization.

A person who is confronted with the many developmental tasks and challenges associated with campus life at the same time they are expected to become more self-reliant tends to feel some pressure. This pressure comes not only from the campus environment, but also from the family environment through parenting. Challenges and pressures from both the family and social environments can affect an individual's mental well-being. Therefore, the purpose of this study is to see whether expressive writing is a successful strategy for decreasing anxiety symptoms. Expressive writing in a diary was the main intervention used in this study. In addition, the researchers also provided progressive relaxation training and expression through drawing at faceto-face meetings as a complementary intervention. Expressive writing, progressive relaxation training, and expression through drawing are assumed to decrease the participant's anxious feelings.

\section{Methods}

\section{Participants}

The participant in this research was a woman currently studying for her bachelor's degree at Universitas Indonesia who had problems overcoming her anxiety. She came to the Student Counseling Board (BKM) Universitas Indonesia to seek help by her own initiative. The BKM 
provides help for university students free of charge. Clients initially register themselves and describe their complaints. Furthermore, the selection of this particular client was by special request from the BKM psychologist to the researcher who was on practical duty. Assessment of client's anxiety level was done by periodic observation, conducting semi-structured interviews to find out the client's background and life history, and the provision of several activities aligned with the client's interests.

\section{Case Introduction}

"Prily" is a 20 year-old Javanese woman studying her second year at Universitas Indonesia. She is the third of four children and has two older brothers and one sister. She lives with her parents and grandparents from her mother's side.

\section{Presenting complaints}

Prily's original complaint upon arrival at BKM was that she was having problems expressing her thoughts and feelings and finding it difficult to speak in front of others. She did not feel confident and was afraid of other people's judgment of what she did. Therefore she often stuttered when talking and could only hope that others would understand her speech. Prily's feeling of anxiety had inhibited her daily activities to the point of seeking help. Prily's hope was that by seeking psychological help she could solve the problem and become more adaptable and also more confident.

\section{History}

During her childhood, Prily lived in Surabaya with her entire family. Before the birth of her sister, she was the first daughter, so she had the role of youngest child for 15 years. At the time she entered elementary school (SD), her father, who worked as a member of the Navy, was assigned to Nigeria. As a result, she and her entire family moved to Nigeria and stayed there for three years. While studying in Nigeria, she was often invited to attend various events at the Embassy of Indonesia, such as regional dance competitions. After three years passed, she returned to Indonesia and continued her education. Prily was very talented and was successful at many achievements. Prily always received support from her teachers and parents. She also would always get what she wanted. Compared to her father, her mother played a more important role and provided for all of Prily's needs. But in high school, especially during eleventh grade, her parents began to restrict Prily's activities, especially extra-curricular activities that she had participated in during junior high school. Her mother thought that Prily should focus more on her school lessons in preparation for entering university. In high school and in college, she felt even more restrained and restricted, including in the matter of choosing partners.

Prily experienced a very unpleasant and unforgettable experience in high school that impacted her life to this day. A senior in high school whom she respected judged her for having excessive attitudes and attention-seeking performances. Since that incident, Prily became more silent and often felt anxious. She worried about other people's opinions and judgments of her. This continued until she went to college. The behavior arising from the anxiety she felt when she expressed her opinions and feelings was stammering. This made other people uncomfortable, especially her close friends, who complained about her behavior. Prily wished that others would understand what she was trying to say even when stammering.

She also felt that she could not argue freely even though she was at home; she had to follow her mother's wishes. Since she was a child, she had always been directed by her parent's orders at 
home. She was not accustomed to expressing her own wishes, and this aggravated her anxiety symptoms. Because of that, she considered herself troubled if she did not have her close friends to help her. She always asked for opinions and judgments from her close friends before making any decision. The anxiety she felt made her feel short of breath because she felt something stuck inside her, and this caused her to stammer when she wanted to talk. Therefore she often stayed silent and chose to simply follow what others were doing or saying.

\section{Assessment results}

Prily dressed according to her age; she had a casual dress style. She wore a veil, braces, and always carried a backpack to every session. At the beginning of the session, the volume and tempo of her speech was slow and halted often, and she often used the phrase "something like that, it's hard to say" if she could not finish the sentence. She often teared up or started crying. Prily also frowned and sat unsteadily, often playing with her fingers and biting her nails. Her intellectual capacity was estimated to be at an average level with sufficient ability to integrate and analyze. Prily had high affection needs. This could be seen from her lack of confidence in making decisions and her inability to plan well so that she desperately needed help or direction from others. One of the factors that could cause this condition was her parents' authoritarian parenting style, in which everything Prily did was directed by her parents. During the session, Prily showed a cooperative attitude toward the researcher. A flow diagram of personality traits related to the anxiety symptoms can be seen in Figure 1, and her multiaxial diagnosis can be seen in Table 1.

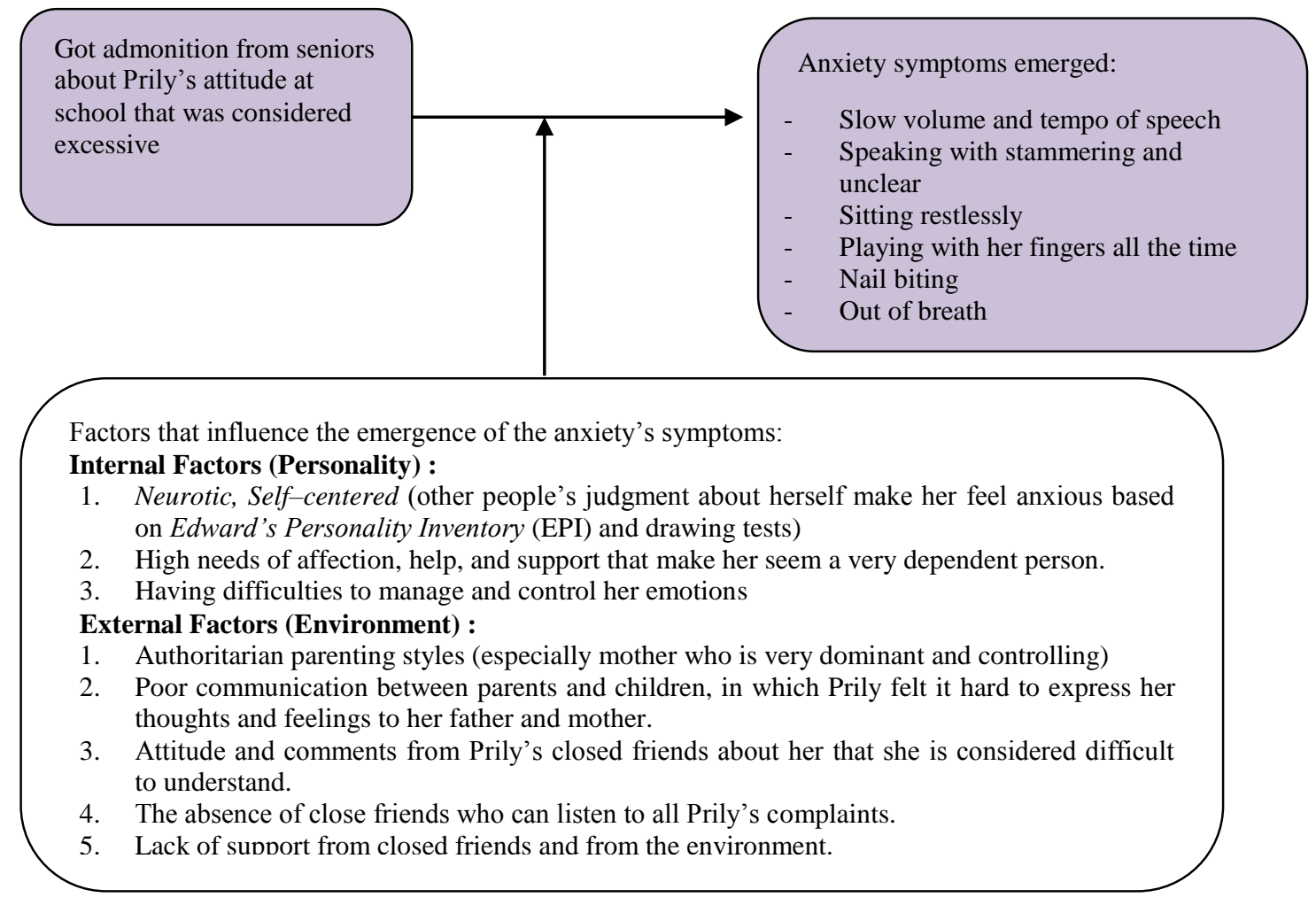

Figure 1. Flow diagram of personality traits related to anxiety symptoms 


\section{Case conceptualization}

This section will explain the conceptualization of Prily's case based on the guidance obtained from Pennebaker (1997), through which expressive writing interventions, i.e., diary writing and drawing activities can help a person. In Prily's case, she had difficulty expressing her thoughts and feelings because it made her feel anxious, causing her to stammer when speaking. The case conceptualization for each of these activities will be explained in the following paragraphs.

Prily's way of speaking in a quiet voice often made others misunderstand what she was saying. The often-unfinished or hanging sentence made it difficult for others to understand the message. When she revealed something and the other person did not understand what she was saying, Prily would cry. She chose to be silent, save her own negative emotions, and follow the will of others rather than try to explain more about her opinions or feelings. She also began to have negative thoughts about how other people would probably always have trouble understanding her, and that she would always need help from her close friends.

\section{Research Design}

The design of this research is a case study to monitor changes that occurred for the participant before, during, and after an intervention. Observation and evaluation for the presence of anxiety symptoms was done at every session for a total of four sessions.

\section{Procedure}

The intervention given to Prily was done intensively and gradually in four sessions over a sevenday period. The researcher made observations in the initial stage. Observations were conducted as the data collection method to see what changes Prily experienced during the first session, the intervention, and the follow-up session. The researcher conducted interventions consisting of (1) counseling (2) guiding questions (3) expressive writing in a diary, and (4) a progressive relaxation exercise that will be described in the following paragraph.

\section{Observation}

The researcher made observations from the beginning of the face-to-face sessions to the followup session. Patton (as cited in Poerwandari, 2017) explained that observation is one of the essential data collection methods in a study. Observation allows researchers to see any changes experienced but not realized by the participant. The researcher recorded all behaviors that occurred in each face-to-face session, including punctuality, dress style, tempo and volume when speaking, words or phrases used most often, movements made during speech, posture, facial expressions, eye contact, and comments made during psychological tests and the interventions.

\section{Counseling}

In Prily's case, counseling was done to determine the problems she felt she was facing. As counselor, the researcher used three conditions based on Rogers (1957): empathy, acceptance, and congruence or genuineness. To show empathy, the researcher in the counseling role reconveyed what the participant disclosed; to show acceptance, the researcher as counselor showed a positive regard and appreciation of the participant's feelings; to show congruence or genuineness, the researcher facilitated the participant understanding that she was present in transparent conditions for therapeutic relations. The researcher as the lead author also counseled for anamnesis, knowing that learning about Prily's background and biography was related to 
understanding her anxiety symptoms. In counseling, the researcher also provided psychoeducation about the relationship between anxiety and stressful situations with physical reactions.

\section{Guiding questions}

Guiding questions were provided to Prily with regard to writing in her diary. These guidance questions were given in the first session before the diary writing activities began. The guiding questions themselves asked about what experiences she had, what feelings accompanied the event, how she reacted to the event, what she thought at the time, and what she thought of the event. By providing guiding questions, the researcher focused on the experiences she would not normally share with other people. As long as the guidance questions were provided, she could understand well and did not experience any significant difficulties.

\section{Expressive writing in diary}

In the beginning, Prily had difficulty expressing herself verbally about her problems during the counseling sessions. When a topic was brought up about a particular event, she would cry and was not able to finish her sentences. The researcher finally asked Prily to write down the things she wanted to tell the researcher. This, Prily was able to do without any obstacles. After that, the researcher asked Prily to discuss her feelings while she was in the BKM environment accompanied by her best friend. Prily was able to write it down fluently without trouble. This condition was quite different compared to when the researcher asked Prily to express it verbally; then she would stagger back, become silent, and then cry. When the researcher asked about her opinion on writing, she said that it allowed her to feel at ease while conveying her opinions and feelings. The researcher also allowed Prily the freedom to write down her feelings from previous events. Furthermore, each time a session ended, the researcher assigned expressive writing in the diary as home work. Prily was instructed to write down her feelings about the events she experienced daily in the diary. Prily was allowed to write without any time limit, and at any time she felt the need to express something. At the beginning of each face-to-face session, the researcher would ask Prily to bring her writing and ask her about her feelings when she finished writing. Prily was also expected to continue writing in the diary even after the sessions ended.

To accompany this intervention, the researcher gave Prily some activities of expression through depiction and progressive relaxation training during the face-to-face sessions. For expressing through depiction, the researcher directed her to draw things she likes, no matter what that was; this was based on her interest and talent in drawing. This was done because Prily said that she could express herself when she was drawing and also that she felt calmer while drawing. The researcher assigned Prily home work to bring the drawing results to the second, third, and fourth sessions. The researcher also allowed Prily to write down her feelings and experiences in the writing diary while drawing. In addition, the researcher provided progressive relaxation training. First, the researcher explained the purpose and benefits of progressive relaxation; then, she was asked to stretch and relax her muscles. After Prily seemed motivated to understand and try the technique, the researcher provided the complete instructions. Prily was asked to sit in a position that she felt most comfortable and follow the researcher's instructions. During the process of giving the technique, Prily did not seem to have constraints. She did the whole technique correctly. This progressive relaxation technique was given in the second and fourth sessions. Each time the technique was given, Prily was asked to reveal what she felt both before and after the technique was given. This was done in order to be able to evaluate as well as observe the effectiveness of the progressive relaxation on Prily's tension and anxiety. Prily was also asked to recall the technique so she that could practice it herself at home. Prily reported that she felt 
relaxed and comfortable after doing the technique. In addition, she was also more aware that she used to be in a constant tense muscular state of anxiety.

\section{Termination}

At the end of the intervention, which was the termination stage, the researcher reviewed the details for each session. This included relaying the initial complaints, what activities were completed, the feelings that accompanied the intervention (both oral and written). In general, based on the intervention activities, Prily revealed that her initial complaints about her anxiety could be channeled into expressive writing in the diary and expressing her thoughts and feelings through drawing.

\section{Data Analysis}

Data analysis was done by comparing the observation results from the initial session before the intervention was given with those gathered by last session, as well as by analyzing the participant's responses throughout. Changes noted in observations of Prily are as follows:

Table 1

Observations of Prily

\begin{tabular}{lcc}
\hline \multicolumn{1}{c}{ Category } & Before Intervention & After Intervention \\
\hline Volume of speech & Very soft (almost whispering) & Clear enough \\
Tempo of speech & Slow & Continue and fluent \\
Content & (frequently) discontinue & "I feel," "I think" \\
Phrase & "something like that," "it's hard to say" & More relaxed \\
Posture & Bending over, away from desk & absent \\
Behaviors during session & Nail biting & absent \\
& Playing with the fingers all the time & absent \\
& Lip licking & Good enough \\
Eye contact & Poor & More relaxed \\
Facial expression & Frowned forehead & Lots of smiles \\
\hline
\end{tabular}

\section{Results}

During and after the intervention, Prily's anxiety symptoms showed a gradual decline. This indicated that the given intervention of writing in the diary was appropriate and successful in helping achieve the reduction of Prily's anxiety symptoms. Her expression through drawing and progressive relaxation training were also proven successful in helping her to feel more relaxed. This could be seen from the results of the summarized observations in Table 1 and also from Prily's responses after the interventions were done simultaneously with progressive relaxation techniques. Progressive relaxation helped Prily understand how her previous mental condition affected her physical condition, especially with how her muscles were always tense. With the new technique, she understood and enjoyed a relaxed state. 
In addition, through counseling provided in the interventions, it was also learned that authoritarian parenting influenced how Prily behaved in her environment. Their influence made her a more dependent person who found it difficult to make plans and decisions.

\section{Follow up}

The researcher did a follow-up session after one week of the intervention and evaluations four to eight weeks after the intervention session. The purpose of this follow-up session was to monitor whether Prily could maintain her progress without the researcher's assistance. Prily reported that with the habit of writing a diary, she no longer found it difficult to express her opinion. She admitted having more courage to talk in small groups and to appear in front of crowds as she followed the faculty activities. She also began to dare to express what she felt about daily events to her best friend.

\section{Discussion}

In general, the results of the intervention decreased the client's anxiety symptoms. The main intervention given was expressive writing in a daily diary. This helped Prily to reduce her anxious feelings about anything.

Writing helped Prily when she felt anxious or had difficulty conveying her opinion or feelings to others. Prily had kept all her experiences to herself. When she wanted to convey something to others, she felt incapable of creating a sentence orally, so that caused her to stammer. However, when she wrote, she totally found comfort in pouring out her opinions and feelings about circumstances or relationships without fear of being judged. On the other hand, when researcher gave her the task of expressing her feelings through depiction, as well as participating in progressive relaxation, the client's apprehensive anxiety decreased. Expressing through depiction and progressive relaxation was done as a complementary intervention in addition to the main intervention. This was done because the researcher assumed that providing both activities would help reduce the client's anxiety. After a noticeable decrease in anxiety symptoms and after the participant was able to maintain expressive writing, expressing through depiction, and progressive relaxation until the researchers performed follow-up, we can conclude that this indicated that the intervention was effective in providing long-term changes for Prily.

In addition to explaining the positive things that Prily feels, we will also discuss the implications of this case on the clinical intervention field, the potential areas for new research, and recommendations for the researcher. One of the obstacles was Prily's passive attitude. In counseling given, the researcher always listened to help understand the problems faced. One external factor that might have obstructed this intervention process was the home environment, where her mom always controlled her activity and made her feel depressed and unsure about her own decisions. She felt that she could not stand on her own and that she always needed help. People from the campus environment sometimes gave negative comments on Prily's progress as well.

Regardless of these barriers, this case study indicates that behavioral therapy still plays an essential role in decreasing the client's apprehensive anxiety. This case study also implies that writing diaries and progressive relaxation are suitable for a young adult experiencing these problems. Expressive writing has been widely used as a therapy. Research conducted by Krpan, 
et al (2013) mentions that forty people diagnosed with Major Depressive Disorder (MDD) significantly decreased their depression scores through expressive writing (Beck Depression Inventory and Patient Health Questionnaire-9 scores) immediately after the experimental manipulation (Day 5). These benefits persisted at the 4-week follow-up.

This case study shows that simple treatment can be done within a relatively short time; that is, even only four sessions can successfully reduce anxiety symptoms. In addition, the success of this intervention at reducing Prily's anxiety symptoms has provided an opportunity for other researchers to develop the intervention provided by analyzing the contents of the diary. In addition, the methods used in this case study could also be replicated on a larger scale by using larger samples, comparison groups, and strict controls on external variables to ensure the causal relationships and contributions provided by the intervention can be seen clearly.

This case study shows that the activity of writing a journal or diary to express emotions during or after any event that a person experiences can have a positive impact on a person's change and adaptability. In addition, diary writing activities are still aligned with people's needs for coping with stress, anxiety, and other maladaptive behaviors. The limitations in this study included not using a reasonable measuring tool to quantitatively measure the client's anxiety level before and after the intervention. The researcher hopes that in the next study, pre and posttest measurements of the participant's anxiety level can be taken in order to gain more measurable. In addition, the researcher also did not analyze more of the writing available in the client's diary. In face-to-face meetings, the client did not allow her writings to be read by the researcher in front of her; she asked that the researcher read them afterwards, and this reduces the opportunity for the researcher and the client to discuss her anxieties in more detail.

\section{References}

Ames, S. C., Patten, C. A. \& Offord, K. p., Pennebaker, J. W., Croghan, I. T., Tri, D. M., Stevens, S. R., Hurt, R. D. (2005). Expressive writing intervention for young adult cigarette smokers. Journal of Clinical Psychology, 61(2), 1555-1570.

Edelman, R. T. (1970). Effects of progressive relaxation on autonomic processes. Journal of Clinical Psychology, 29(4), 421425.

Francis, M. E., \& Pennebaker, J. W. (1992). Putting stress into words: The impact of writing on physiological, absentee, and selfreported emotional well-being measures. American Journal of Health Promotion, 6(4), 280-287.

Keeling, L. M., \& Bermudez, M. (2006). Externalizing problems through art and writing: Experience of process and helpfulness. Journal of Marital and Family Therapy, 32 (4), 405-419.

Kring, L. A. (2014). The science of psychology: An appreciative view (3th ed.). New York, NY: McGraw Hill.

Kring, L. A. M., Johnson, S. L., Davison, G., \& Neale, J. (2012). Abnormal psychology (12 ${ }^{\text {th }}$ ed.). Hoboken, NJ: John Wiley \& Sons, Inc.

Krpan, K. M., Kross, E., Berman, M. G., Deldi, P. J., Askren, M. K., Jonides, J. (2013). An everyday activity as a treatment for depression: The benefits of expressive writing for people diagnosed with major depressive disorder. Journal of Affective Disorder, 150(2013), 1148-1151.

Mahmoud, J. S. R., Staten, R. T., Hall, L. A., Lennie, T. A. (2012). The relationship among young adult college student's depression, anxiety, stress, demographics, life satisfaction, and coping styles. Issues in Mental Health Nursing, 33:149156.

Meadows, S. O., Brown, J. S., \& Elder, G. H. (2006). Depressive symptoms, stress, and support: Gendered trajectories from adolescence to young adulthood. Journal of Youth and Adolescence, 35(1), 89-99.

Murnahan, B. (2010). Stress and anxiety reduction due to writing diaries, journals, e-mail, and weblogs. Eastern Michigan University. Retrieved from http://commons.emich.edu/honors

Papalia, Olds, \& Feldman. (2009). Human Development (11 $1^{\text {th }}$ ed.). New York: The McGraw-Hill Companies, Inc.

Pennebaker, J.W. (1997). Writing about emotional experiences as a therapeutic process. Psychological Science, 8, $162-166$.

Poerwandari, E. K. (2017). Pendekatan kualitatif untuk penelitian perilaku manusia. Depok: LPSP3 UI.

Rice, F. P. (1996). The Adolescence: Development, Relationship, and Culture ( $8^{\text {th }}$ ed.). Massachussets: Allyn and Bacon 
Rogers, C. R. (1957). The necessary and sufficient conditions of therapeutic personality change. J. consult. Psychology, 21, 95103.

Santrock, J. (1995). Life-Span Development, 5th Edition. New York: McGraw Hill, Inc.

Santrock, J. (2001). Adolescence ( $8^{\text {th }}$ ed.). New York: McGraw Hill, Inc

Shri, R. (2010). Anxiety: Causes and management. International Journal of Behaviora Science, 5 (1), 100-118.

Sloan, D.M., \& Marx, B.P. (2004a). Taking pen to hand: Evaluating theories underlying the written disclosure paradigm. Clinical Psychology: Science and Practice, 11, 121-137. 